\title{
Evaluation of Improved Safety Management Program for Outpatient Drug Dispensing in Terms of Effect on Potential Adverse Drug Events
}

\author{
KEIKO MORITA \\ Department of Hospital Pharmacy, Kurume University School of Medicine, \\ Kurume 830-0011, Japan
}

\begin{abstract}
Summary: Dispensing errors may cause serious health damage. To eradicate dispensing errors, we implemented new safety management strategies, including the development of a dispensingsupport system with a computerized check function. We previously evaluated and reported the usefulness of these new strategies for safety management by comparing the incidence of potential adverse drug events (PADEs) before and after the implementation of these strategies. In the present study, we compared the incidence of PADEs from outpatient prescriptions in the late phase 5 years after the start of the new safety management program with that before the implementation. The incidence of PADEs from outpatient prescriptions after the start of these strategies (late phase) was significantly lower than that before their introduction $(p<0.001)$, similar to the results in the early phase. When examining PADEs with respect to category, the incidence of PADEs related to the dispensing of a wrong drug, such as those related to errors in the drug name or standard/dosage form of the same drug, in the late phase was significantly lower than that before the new program began $(p<0.05)$, as was also the case in the early phase. The incidence of PADEs related to errors in counting tablets/capsules was also significantly lower $(p<0.01, p<0.05)$. With respect to the level of influence on patients (level 0 to $3 a$ ), the incidence of level-0 PADEs, which represents potential errors that were prevented, in the late phase was significantly lower than that before implementation $(p<0.01)$, as was also demonstrated in the early phase. The incidence of level-1 PADEs in the late phase was significantly lower than that before implementation $(p<0.05)$, but not in the early phase. No level-2 or higher PADE occurred in the early or late phases after the start of the new safety program. When the PADEs were examined with respect to possible contributing factors, the incidences of PADEs associated with the presence of multiple standards in the early and late phases were significantly lower than that before $(p<0.05)$. These results suggest the long-term usefulness of this series of newly introduced strategies for safety management.
\end{abstract}

Key words safety management, dispensing error, prescription, dispensing-support system

\section{INTRODUCTION}

In Japan, specific functional hospitals were obligated to establish a safety management system in 2000 [1] based on the background of frequent medical accidents [2-5].

In addition, to further promote medical safety, a medical safety countermeasure network-establishing plan was initiated in 2001 , and medical facilities were asked to cooperate in the collection of incident episodes [6].

At the Department of Pharmacy in the Kurume University Hospital, work procedures have been improved [7-10], targeting drug efficacy/safety as a

Received for publication March 26, 2004

Correspondence to: Keiko Morita, Ph.D, Department of Pharmacy, Kurume University School of Medicine, 67 Asahi-machi, Kurume 830 0011, Japan. Tel: 81-942-35-3311 Fax: 81-942-31-7725 E-mail: morita_keiko@kurume-u.ac.jp

Abbreviations: PADEs, potential adrerse drug events. 
priority. In particular, we have established strategies for safety management $[7,8,11]$, including the development of a dispensing-support system with a computerized check function to protect patients by eradicating dispensing errors. We previously evaluated and reported [7] the usefulness of these new strategies for safety management by comparing the incidence of potential adverse drug events (PADEs) before and after the implementation of the strategies. In this study, we compared the incidences of PADEs from outpatient prescriptions in the early and late (5 years after the start) phases after the implementation of the new strategies with that before the implementation to evaluate their long-term usefulness.

\section{SUBJECTS AND METHODS}

\section{Subjects and period}

Of the $1,244,338$ patients who visited the outpatient clinics of the Kurume University Hospital between January 1997 and January 2004, all patients who received outpatient prescriptions were the subjects of this investigation. The study period was divided into 3 phases, the phase from January 1997 until January 1998 (before the new strategies for safety management were initiated), the early phase after the start of the program (from January 2001 until September 2001), and the late phase, 5 years after the start of the strategies (from April 2003 until January 2004).

\section{Methods}

The incidence of PADEs from outpatient prescriptions given to the subjects was compared among the 3 phases. In this study, episodes in which an error in the dispensing process was missed in internal audits were classified as PADEs, as defined by the Ministry of Health, Labor and Welfare [6].

Safety management approaches prior to introduction of the new strategies

During this period there was no prescriptionordering system for outpatients; prescription orders were handwritten. The pharmacist mainly checked each step of the dispensing process (prescription audit $\rightarrow$ drug preparation/audit $\rightarrow$ final audit $\rightarrow$ guidance for taking medicine). When an incident occurred, pharmacists involved in the incident were obliged to submit a PADE report.

\section{New strategies for safety management}

The new dispensing-support system with computerized check functions consists of a client-server system in which prescription data is transmitted to a server from the host computer of the prescriptionordering system, and the server is connected to various dispensing devices. After our new program was initiated, this computer check function was added to the checks performed by the pharmacist [7].

Automatic check on drug interactions/double prescriptions: In the prescription audit process, we introduced an automatic computerized system to check on drug interactions and double administrations of the same drug.

Automatic indication of the total dosage and discrimination codes of drugs: A dispensing worksheet column was included on the outside part of the outpatient prescription forms issued by prescriptionprinting machines, and the total dosage and discrimination codes of the prescribed drugs were automatically printed out by computer, and utilized to check the prescriptions.

Red indications were added for high risk drugs and easily confused drugs:

Alarm transmission and output of a dispensingrecord sheet: Dispensing was performed using the powder/solution dispensing audit-supporting system. Dispensing records were saved on a computer, and a dispensing-record sheet was printed out and used for checking. When a wrong drug was weighed, an alarm sounded. Concerning powders and solutions, dispensed prescriptions were reconfirmed using a dispensing-record sheet attached to the prescription.

Information on prescribed drugs: By issuing the drug information codes, information on prescribed drugs, such as photo images, drug name, effects, side effects, cautions in daily living, and storage instructions, was provided to patients $[8,12]$.

Marking of changes from the initial/former prescription: Changes from the initial/former prescription (change of dose, additional medications) were automatically indicated by marks in the column for detailed explanation on the dispensing worksheet. Patients were instructed to confirm that the drugs they received matched the photo images.

Therapeutic drug-level monitoring: Concerning drugs where blood concentration was monitored, the department concerned was informed of the measurement results relative to the intoxication range, and dispensing records were confirmed.

Review of the internal regulations for dispensing and the work procedures manual established by the Department of Pharmacy: 
Preparation of a manual on strategies for preventing drug-related accidents:

Preparation of a summary of drugs similar to each other in drug name, container, package, indication, or mode, and a summary of the doses of drugs for children:

\section{Submission of reports on dispensing PADEs [13]:}

Evaluation of the new strategies for safety management, comparison among the 3 phases (prior to the start of the strategies, and the early and late phases after their introduction)

Number and incidence of PADEs from outpatient prescriptions: The number of PADEs from outpatient prescriptions was investigated based on the corresponding prescriptions and PADE reports for each period, and the incidences of PADEs were calculated accordingly.

Number and incidence of PADEs from outpatient prescriptions by category: The PADEs from outpatient prescriptions were classified by category, and the incidence of PADEs for each category was calculated from the prescriptions for each period. The PADEs were classified into the following 8 types in reference to the categories described by the Ministry of Health, Labor [6] and Welfare and the Japanese Pharmaceutical Society [14]. Dispensing of a wrong drug (errors related to drug name or standard/dosage form of the same drug), errors in counting tablets/capsules, errors in weighing powder/solution, delivery omitted, dispensing omitted, delivery errors, errors in dividing and packaging of powder drugs, others.

Number and incidence of PADEs with respect to contributing factors involved in dispensing of a wrong drug in outpatient prescriptions: The PADEs related to dispensing of a wrong drug in outpatient prescriptions were classified with respect to contributing factors, and the incidences of these PADEs with respect to contributing factors were calculated for each period from the corresponding prescriptions. With respect to contributing factors, the PADEs were classified into the following 5 types in reference to the categories described by the Ministry of Health, Labor and Welfare [6]: existence of multiple standards, resemblance in drug efficacy, poor placement (adjacent place of storage), resemblance in the drug name, others.

Number and incidence of PADEs with respect to the influence level in outpatient prescriptions: The PADEs from outpatient prescriptions were classified with respect to influence level, and the incidence of
PADEs with respect to the influence level was calculated for each period from the corresponding prescriptions.

The influence level was classified into the following 4 grades in reference to the categories described by the Ministry of Health, Labor and Welfare and national university hospitals [6,15-17]: Level 0 (error was prevented), Level 1 (error occurred, but there was no influence on the patient), Level 2 (disorders were transient and mild, and no treatment was required), Level 3a (disorders were transient and moderate, and simple treatment was required).

\section{Statistical analysis}

The incidence of PADEs was evaluated. Each parameter was compared among the 3 phases (prior to implementation of the new strategies, and the early and late phases after implementation) using the chi square test. $p<0.05$ was regarded as significant.

\section{RESULTS}

During the 13 months prior to the start of the new program (from January 1997 until January 1998), 249,836 outpatient prescriptions were issued. During the 9 months of the early phase after the start of the program (from January 2001 until September 2001), 249,833 outpatient prescriptions were issued. During the 10 months of the late phase, 5 years after the start (from April 2003 until January 2004), 255,823 outpatient prescriptions were issued. As shown in Table 1 , PADEs occurred in 41 prescriptions in the early phase after the start of the program and in 42 in the late phase. These numbers were significantly lower $(\mathrm{p}<0.001)$ than that prior to the start (79). Concerning the numbers/incidences of PADEs related to dispensing of a wrong drug and to errors in counting tablets/capsules, the percentages in the early and late phases were significantly lower than those prior to the start $(p<0.05)$. The numbers/incidences of PADEs related to errors in weighing powder/solution or of omitted delivery in the early and late phases were slightly lower those prior to the start.

There was no difference in the number/incidence of PADEs related to the dispensing omitted category between the early phase and the pre-implementation period. The incidence in the late phase was slightly lower than before implementation. One incident occurred due to a contributing factor prior to the start; however, no episode occurred in the early or late phases. Table 2 shows the number and incidence 
TABLE 1.

PADEs in the outpatient prescriptions

\begin{tabular}{|c|c|c|c|c|c|c|}
\hline \multirow{2}{*}{ Item } & \multicolumn{2}{|c|}{$\begin{array}{c}\text { Before initiation } \\
n=249,836\end{array}$} & \multicolumn{2}{|c|}{$\begin{array}{c}\text { After initiation } \\
\text { (early phase) } n=249,833\end{array}$} & \multicolumn{2}{|c|}{$\begin{array}{c}\text { After initiation } \\
\text { (late phase) } n=255,832\end{array}$} \\
\hline & $\begin{array}{l}\text { Number of } \\
\text { episodes }\end{array}$ & Incidence & $\begin{array}{l}\text { Number of } \\
\text { episodes }\end{array}$ & Incidence & $\begin{array}{l}\text { Number of } \\
\text { episodes }\end{array}$ & Incidence \\
\hline Dispensing of a wrong drug & 35 & $0.0140 \%$ & 18 & $0.0072 \% *$ & 20 & $0.0078 \% *$ \\
\hline $\begin{array}{l}\text { Errors in counting } \\
\text { tablets/capsules }\end{array}$ & 26 & $0.0104 \%$ & 10 & $0.0040 \% * *$ & 11 & $0.0043 \% *$ \\
\hline $\begin{array}{l}\text { Errors in weighing } \\
\text { powder/solution }\end{array}$ & 4 & $0.0016 \%$ & 2 & $0.0008 \%$ & 2 & $0.0008 \%$ \\
\hline Delivery omitted & 5 & $0.0020 \%$ & 4 & $0.0016 \%$ & 2 & $0.0008 \%$ \\
\hline Dispensing omitted & 5 & $0.0020 \%$ & 5 & $0.0020 \%$ & 3 & $0.0012 \%$ \\
\hline Delivery errors & 1 & $0.0004 \%$ & 0 & $0.0000 \%$ & 1 & $0.0004 \%$ \\
\hline $\begin{array}{l}\text { Errors in dividing and } \\
\text { packaging of powder drugs }\end{array}$ & 2 & $0.0008 \%$ & 2 & $0.0008 \%$ & 3 & $0.0012 \%$ \\
\hline Others & 1 & $0.0004 \%$ & 0 & $0.0000 \%$ & 0 & $0.0000 \%$ \\
\hline Total & 79 & $0.0316 \%$ & 41 & $0.0164 \% * * *$ & 42 & $0.0164 \% * * *$ \\
\hline
\end{tabular}

Before initiation vs After initiation (early phase)/(late phase)

${ }^{*} \mathrm{p}<0.05, * * \mathrm{p}<0.01, * * * \mathrm{p}<0.001$

TABLE 2.

PADEs related to dispensing of a wrong drug in outpatient prescriptions

\begin{tabular}{|c|c|c|c|c|c|c|}
\hline \multirow{2}{*}{$\begin{array}{l}\text { Contributing factors } \\
\text { involved in dispensing } \\
\text { of a wrong drug }\end{array}$} & \multicolumn{2}{|c|}{$\begin{array}{c}\text { Before initiation } \\
n=249,836\end{array}$} & \multicolumn{2}{|c|}{$\begin{array}{c}\text { After initiation } \\
\text { (early phase) } n=249,833\end{array}$} & \multicolumn{2}{|c|}{$\begin{array}{l}\text { After initiation } \\
\text { (late phase) } n=255,823\end{array}$} \\
\hline & $\begin{array}{l}\text { Number of } \\
\text { episodes }\end{array}$ & Incidence & $\begin{array}{l}\text { Number of } \\
\text { episodes }\end{array}$ & Incidence & $\begin{array}{l}\text { Number of } \\
\text { episodes }\end{array}$ & Incidence \\
\hline Presence of several standards & 18 & $0.0072 \%$ & 8 & $0.0032 \% *$ & 6 & $0.0023 \% *$ \\
\hline Resemblance in drug efficacy & 5 & $0.0020 \%$ & 2 & $0.0008 \%$ & 1 & $0.0004 \%$ \\
\hline $\begin{array}{l}\text { Poor displacement (adjacent } \\
\text { place of storage) }\end{array}$ & 5 & $0.0020 \%$ & 2 & $0.0008 \%$ & 3 & $0.0012 \%$ \\
\hline $\begin{array}{l}\text { Resemblance in the drug } \\
\text { name }\end{array}$ & 6 & $0.0024 \%$ & 6 & $0.0024 \%$ & 8 & $0.0031 \%$ \\
\hline Others & 1 & $0.0004 \%$ & 0 & $0.0000 \%$ & 2 & $0.0008 \%$ \\
\hline Total & 35 & $0.0140 \%$ & 18 & $0.0072 \% *$ & 20 & $0.0078 \% *$ \\
\hline
\end{tabular}

Before initiation vs After initiation (early phase)/(late phase) $\quad * \mathrm{p}<0.05$

of PADEs related to dispensing of a wrong drug with respect to contributing factors in outpatient prescriptions. Concerning the numbers/incidences of PADEs related to the existence of multiple standards, the percentages in the early and late phases were significantly lower than that prior to the start $(p<0.05)$. In addition, the numbers/incidences of PADEs related to resemblance in drug efficacy/poor placement (adjacent place of storage) in the early and late phases were slightly lower than that prior to the start. Table 3 shows the number and incidence of PADEs from outpatient prescriptions with respect to the influence level. Concerning the numbers/incidences of level- 0 PADEs, the percentages in the early and late phases were significantly lower than that prior to the start $(\mathrm{p}<0.01)$. For level-1 PADEs, the percentage in the early phase was slightly lower than that prior to the start. However, the percentage in the late phase was significantly lower than that prior to the start $(\mathrm{p}<$ $0.05)$. No level-2 incident occurred prior to the start of the new program or in the early/late phases. A level-3a incident occurred in 1 prescription prior to 
TABLE 3.

$P A D E s$ in outpatient prescriptions

\begin{tabular}{|c|c|c|c|c|c|c|c|}
\hline \multirow{2}{*}{ Item } & \multirow{2}{*}{$\begin{array}{l}\text { Influence } \\
\text { level }\end{array}$} & \multicolumn{2}{|c|}{$\begin{array}{c}\text { Before initiation } \\
n=249,836\end{array}$} & \multicolumn{2}{|c|}{$\begin{array}{c}\text { After initiation } \\
\text { (early phase) } n=249,833\end{array}$} & \multicolumn{2}{|c|}{$\begin{array}{c}\text { After initiation } \\
\text { (late phase) } n=255,823\end{array}$} \\
\hline & & $\begin{array}{l}\text { Number of } \\
\text { episodes }\end{array}$ & Incidence & $\begin{array}{l}\text { Number of } \\
\text { episodes }\end{array}$ & Incidence & $\begin{array}{l}\text { Number of } \\
\text { episodes }\end{array}$ & Incidence \\
\hline $\begin{array}{l}\text { Errors were } \\
\text { prevented }\end{array}$ & 0 & 68 & $0.0272 \%$ & 37 & $0.0148 \% * *$ & 40 & $0.0156 \% * *$ \\
\hline \multirow{3}{*}{$\begin{array}{l}\text { Errors occurred } \\
\text { in patients }\end{array}$} & 1 & 10 & $0.0040 \%$ & 4 & $0.0016 \%$ & 3 & $0.0012 \% *$ \\
\hline & 2 & - & - & - & - & - & - \\
\hline & $3 a$ & 1 & $0.004 \%$ & - & - & - & - \\
\hline Total & & 79 & $0.0316 \%$ & 41 & $0.0164 \% * * *$ & 42 & $0.0164 \% * * *$ \\
\hline
\end{tabular}

Before initiation vs After initiation (early phase)/(late phase)

${ }^{*} \mathrm{p}<0.05, * * \mathrm{p}<0.01, * * * \mathrm{p}<0.001$

the start. No episode occurred in the early or late phases.

\section{DISCUSSION}

To provide safe and high-quality medical care, medical professionals should develop strategies for safety management based on the proverb "To Err is Human" $[2,3,13,15,17]$. In the strategies for safety management that we established, a computerized check function was employed at each stage of a dispensing process that had formerly depended on manual audits. In outpatient dispensing, there are many factors that can induce human errors, such as the issuing of many prescriptions in a concentrated period during peak hours in outpatient clinics.

However, the incidence of PADEs from outpatient prescriptions after the start of the new program (late phase) was significantly lower than that before the start, as was also the case in the early phase after the start. This may have been because the total dosages and discrimination codes for drugs were automatically printed out by computer in the dispensing worksheet, and drug information codes with photo images facilitated confirmation of dispensed drugs. In addition, the decrease may have been associated with standardization of the dispensing process and "learning from instances" [3-5,17,18] based on reports on PADEs.

There was no marked difference in the incidence of PADEs related to errors in weighing powder/solution in outpatient prescriptions before and after the introduction of the new program; this may have been because the new system could not be utilized after midnight when the computer had stopped, despite a large amount of dispensing during this time period. After the new strategies for safety management were initiated, reconfirmation of dispensed prescriptions was performed with respect to powder and solution; therefore, no errors were made. However, we consider that the prescription-ordering system should function for $24 \mathrm{hrs}$.

Contributing factors involved in PADEs related to dispensing of a wrong drug included resemblance in drug efficacy, existence of multiple standards, poor displacement (adjacent place of storage), and resemblance in the drug name, as reported by Kano $[18,19]$. The incidences of PADEs related to the presence of multiple standards in the early and late phases were significantly lower than that prior to the start. This may have been because the discrimination codes for drugs were automatically printed out by computer in the dispensing worksheet, and this may have facilitated confirmation of the drugs.

Pharmacists help to prevent physicians from making prescription errors, since pharmacists are obliged by Article 24 of the Pharmacist Law to ask questions when necessary $[12,20]$ In the Kurume University Hospital, 219 prescription errors by physicians occurred in 2001; however, we intercepted them in the course of prescription audits. Nevertheless, dispensing errors related to errors in prescription audits may occur; therefore, communication of patient information, including the disease name, between physicians and pharmacists is needed.

The incidences of influence level-0 PADEs were 
significantly lower in the early and late phases than that prior to the start; however, this may have been related to a decrease in the total incidence of PADEs, because level-0 PADEs occurred in $68(86.08 \%)$ of the 79 PADEs prior to the start of the new strategies, in $37(90.24 \%)$ of the 41 PADEs the early phase, and in $40(95.24 \%)$ of the 42 PADEs in the late phase, comprising the highest percentage of total PADEs.

The incidence of level-1 PADEs was significantly lower in the late phase. No level-2 or higher incident occurred in the early or late phases. To improve the safety of drug therapy, Kohn et al. [3] proposed that patients should have knowledge about treatment. In the Kurume University Hospital, the initial prescription, addition of drugs, and change of the dose indicated by physicians are automatically indicated by marks in the dispensing worksheet, and these matters are explained verbally and by using the drug information codes when screening indicate a requirement for detailed explanation. In addition, patients are instructed to confirm their drugs in reference to photo images. This may contribute to improvement in the patient's recognition of drug therapy and safety. Reconfirmation of dispensed prescriptions and self-checks on dispensing may also have contributed to the significant decrease in the incidence of PADEs. In the future, with respect to anticancer, antidiabetic, digitalis preparations, and warfarin preparations, in which dispensing errors may lead to serious health consequences, the dispensing method should be examined in accordance with drug history.

The new computerized program for safety management in drug dispensing in the Kurume University Hospital markedly decreased the incidence of PADEs from outpatient prescriptions over a long period. In the future, continuous improvements should be made to further eradicate dispensing errors.

ACKNOWLEDGMENTS: We thank the staff of the Department of Pharmacy at the Kurume University Hospital for establishing the improved safety management strategies for drug dispensing, and for data collection on PADEs.

A portion of this study was presented at the 119 th Annual Meeting held by the Japanese Society of Pharmacy (Tokushima City), the 27 th General Meeting held by the Japanese Society of Pediatric Clinical Pharmacology (Kurume City), and the 62 nd General Meeting held by the Kyushu Yamaguchi Society of Pharmacy (Kagoshima City).

\section{REFERENCES}

1. Notification from the General Manager, Health Strategy
Bureau, Ministry of Health and Welfare. Maintenance of the safety management system in specific function hospitals. General Affairs Division Issue No. 13, 2000. (in Japanese)

2. Brennan TA, Leape LL, Laird NM, Hebert L, Localio AR et al. Incidence of adverse events and negligence in hospitalized patients. Results of Harvard Medical Practice Study 1. N Engl J Med 1991; 324:370-376.

3. Kohn LT, Corrigan JM, and Donaldson MS. To Err is human. Building a safer health system. Washington, National Academy Press, 1999.

4. Bates DW, Cullen DJ, Laird N, Petersen LA, Small SD et al. Incidence of adverse drug events and potential adverse drug events. JAMA 1995; 274:29-43.

5. Leape LL, Bates DW, Cullen DJ, Cooper J, Demonaco HJ et al. Systems analysis of adverse drug events. JAMA 1995; 274:35-43.

6. Notifications from the Director of the Medical Politics Bureau/Director of the Pharmaceutical and Food Safety Bureau, Ministry of Health, Labor and Welfare. Cooperation in medical safety strategy network-establishing plan. Medical Politics Bureau Issue No. 1036/Pharmaceutical Bureau Issue No. 1139, 2001. (in Japanese)

7. Morita K. Safety management measures in dispensing and their evaluation. J Kurume Med Assoc 2002; 65:203215. (in Japanese)

8. Morita K. Supply of drug information to outpatients in the Department of Pediatrics. Jpn j dev pharmacol ther 2001; 14:36-41. (in Japanese)

9. Nakagaki H, Morita K, and Noda S. A means of drug administration to children: Sodium valproate suppository. Jpn $\mathrm{j}$ dev pharmacol ther 2001; 14:8-10. (in Japanese)

10. Inoue M, Tanaka K, Nagata I, Morita $Y$, and Noda S. Preparation of anti-malignant tumor drugs in the Department of Pharmacy and review in the pediatric field. Jpn j dev pharmacol ther 2001; 14:15-16. (in Japanese)

11. Motomura K, Tsuruta M, Takamatsu H, Morita K, and Noda S. Strategies for preventing incidents associated with medicines. Jpn j dev pharmacol ther 2001; 14:5862. (in Japanese)

12. Bond CA, Raehl CL, and Franke T. Clinical pharmacy services, hospital pharmacy staffing and medication errors in United States hospitals. Pharmacotherapy 2002; 22:134-47.

13. Cohen MR. Why error reporting systems should be voluntary. Br Med J 2000; 320:728-729.

14. Inoue S. Performance of the medical safety-promoting week and submit of “incident reports". J Jpn Soc Hosp Pharm 2001; 53:1547-1552. (in Japanese)

15. National University School of Medicine Hospital Directors' Meeting. Establishment of safety management systems for preventing medical incidents [Proposal]. Tokyo, Nissoken, pp1-167, 2002. (in Japanese)

16. Nakajima K, Yata K, and Takeda H. Clinical risk management: Nursing practice. Tokyo, Bunkodo, pp1-242, 2003. (in Japanese)

17. Wolff AM, Bourke J, Campbell IA, and Leembruggen 
DW. Detecting and reducing hospital adverse events, outcomes of the Wimmera clinical risk management program. Med J Aust 2001; 174:621-625.

18. Carriere B, Bailey B, Chabot G, and Lebel D. Dispensing error leading to alendronate ingestion. Ann Pharmacother 2003; 37:87-89.

19. Kano H. Prevention of medical incidents in reference to episodes, medical incidents and prevention in the comedical department, medical incidents in the department of pharmacy: Prevention of dispensing incidents. Body Science 2000; Extra edition: 38-43. (in Japanese)

20. Blum KV, Abel SR, Urbanski CJ, and Pierce JM. Medication error prevention by pharmacists. Am J Hosp Pharm 1988; 45:1902-1903. 